\title{
S3. Psychiatric training in Europe
}

PSYCHIATRIC TRAINING IN EUROPE

George N. Christodoulou

President, European Board of Psychiatry, Department of Psychiatry, University of Athens, 74 Vasilissis Sofias Ave., 11528 Athens, Greece

It is doubtful whether European Psychiatry (as a comprehensive system of scientific thought and practice, common to all European countries) really exists and it would be more logical to talk about European Psychiatries rather than European Psychiatry.

However, common characteristics can be traced in spite of the differences and this is particularly obvious lately as a result of enhancement of communication, exchange of scientific information, common diagnostic systems etc. Establishment of the Union Europeéne des Medecins Specialistes (U.E.M.S.) following the 1958 Treaty of Rome, and specifically of the Psychiatry Section of the U.F.M.S. in April 1992 and of the European Board of Psychiatry in October 1992 has helped in the identification of the goals and perspectives of practice and particularly training in the recording of the differences in training between the involved countries and in the "harmonization" of training and practice in the European Union countries. Among the means by which the training of the specialist doctor can be "raised to the highest possible level" (European Boards of the U.E.M.S Draft Statutes, Document D, 9121/TER. October 1991) are:recommendations about the standards required for the training of specialists, proposals for the quality of training and the syllabus of each specialty, recomendations concerning the criteria to which the training centres should conform, examination of content and quality of training in the different countries, facilitation of exchange of trainees between training centres and setting of a system for "recognition of qualification" or "European Board Qualification". European integration in Psychiatry is a very important issue, in which in addition to the relevant bodies of the European Union, like the U.E.M.S., the European scientific societies, like the European Psychiatric Association, should also get involved.
PSYCHIATRIC TRAINING IN CENTRAL AND EASTERN EUROPE Cyril Hösch!

$3^{\text {rd }}$ Medical Faculty, Charles University \& Prague Psychiatric Center, Prague, Czech Republic

The Czech system of undergraduate and postgraduate training can be described as a representative example of psychiatric education in Central and Eastern Europe (CEEC), as its structure was quite uniform all over the former communistic block.

Undergraduate Education

Medical education in Czech Republic includes basic sciences, does not require college grade and lasts six years. The goals of a medical student curriculum in psychiatry are: a) understanding of the basis of mental disorders, b) of human development, c) of theoretical background, d) to diagnose major mental disorders, e) to suggest relevant treatment, $f$ ) to interest some students in entering psychiatry etc.

Postgraduate training

Postgraduate education (PGE) was organized as an external education by Postgaduate Institute in two grades: first grade taking 2.5 year including 3 months internship in surgery and 3 months in internal medicine, and second grade requiring additional 3 years. Each grade was conditioned by both oral examination and interviewing a patient with consequent case analysis including therapeutic plan. Child psychiatry, geriatrics, sexuology, alcohology etc. have an extra speciaization requiring at least first grade in psychiatry or related discipline as a basis. According to a new law, also universities and recog nized hospitals can provide PGE. Examination will be independent, based on national level. There will be only one grade of specialization.

C.M.E.

Continuous medical education is organized by the Postgraduate Institute and by various medical societies. Universities only recently obtained equal rights to participate in postgraduate education. The whole structure of psychiatric education is changing now, particularly on the postgraduate level.

I can be concluded, that the more pragmatic orientation of the curriculum, greater participation in a clinical work and more complex and standardized examination is what should be done in CEEC including extension of psychiatric courses. 
THE FIRST EXPERIENCE OF USING FOREIGN PSYCHIATRISTS IN TRAINING OF RUSSIAN DOCTORS

P. Sidorov, A. Kalinin

Medical Institute, Department of Psychiatry, Troitskii Prospekt, 51, Arkhangelsk, 163061, Russia

The actual problem of today is the integration of foreign world clinical medicine. It is especially important for Russian psychiatry where artificial ideological views has been the obstacles for using prohibited Western psychotherapeutic methods.

The department of Psychiatry of Arkhangelsk Medical Institute (AMI) jointty with the German Association of Positive Psychotherapy (GAPP) has organized an educational course for Russian psychiatrists on Positive Psychotherapy. The educational process consists of 5 stages. The participants who have gone through all stages and successfully passed the exams received the Diploma of GAPP.

As a result of such collaboration was the foundation of Russian-German Centre of Positive Psychotherapy formed on the base of AMI. The Centre has the functions of coordination and development of the psychotherapeutic method in Russia.
PARALLEL ICD-9/ICD-10 DIAGNOSTICS OF 50 PSYCHIATRISTS IN POSTGRADUATE TRAINING P.Smolik Postgraduate Medical Institute, Prague, Czech Republic

ICD-10 contemporary with ICD-9 psychiatric diagnostics has been used obligatory in order to pass a practical part of psychiatric examination in Prag's Postgraduate Medical Institute since the year 1991.

Analysis of 50 cases was carried out with evaluation of diagnostic reliability, confidence, and problems of the transfer from ICD-9 to ICD-10 psychiatric classification. Both diagnostic reliability and confidence have been found to be on a very high level and only sporadic problems in the process of the diagnostical transfer from ICD-9 to ICD-10 classification have occured.
PROGRAM OF INTEGRATIVE PSYCHOTHERAPY TRAINING FOR RESIDENTS IN PSYCHIATRY

AW Szafran

Faculty of Medicine of the V.U.B., Head of the Department of Psychiatry, Academic Hospital of the V.U.B., Laarabeeklaan 101, 1090 Brussels, Belgium.

The author defends the viewpoint that in opposition to the legislator, a training in psychotherapy must be maintained as part of the residency in psychiatry. He makes a review of existing training modes and proposes an "integrative" training model, open to the great psychotherapeutical orientations. 